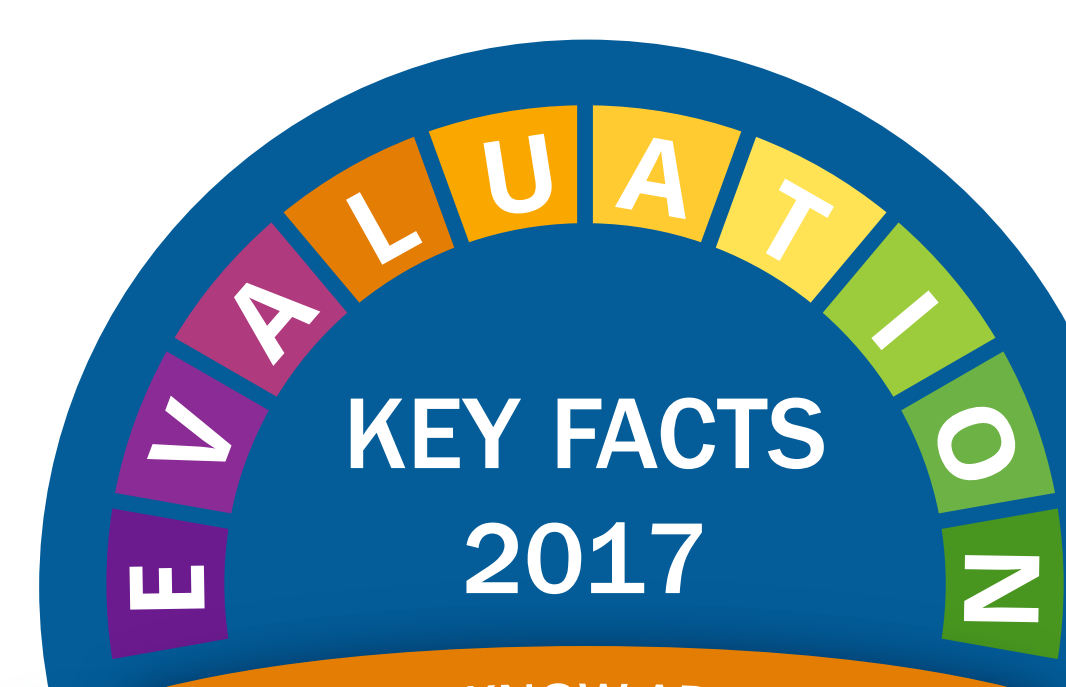

WHAT WE KNOW ABOUT HOW FOUNDATIONS USE AND SHARE EVALUATIONS

In 2017 Foundation Center surveyed a sample of U.S.-based foundations about whether they conduct evaluations, what they evaluate, and whether they share what they learn outside of their organization. Here's what we learned.

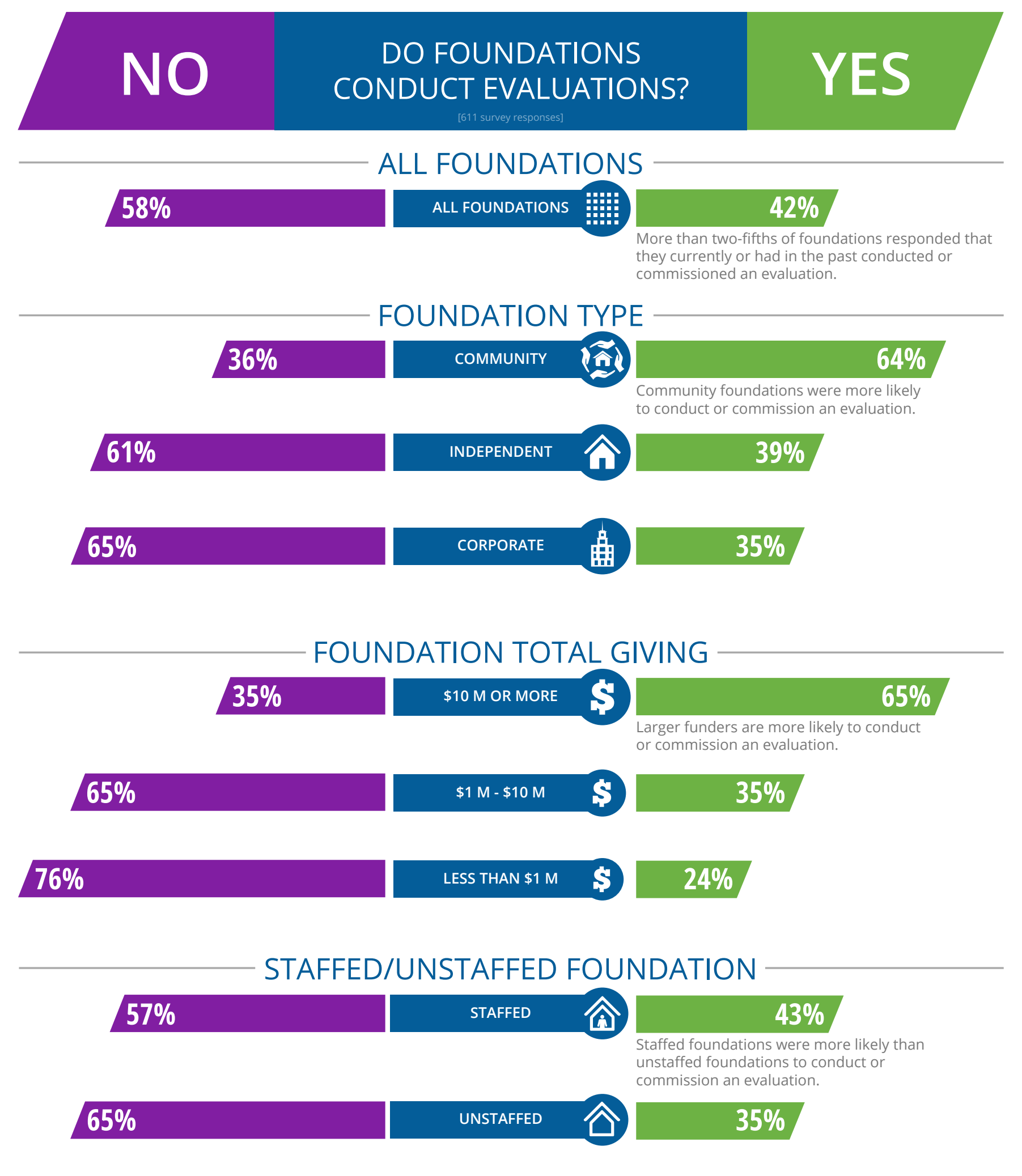

WHAT DO FOUNDATIONS EVALUATE?

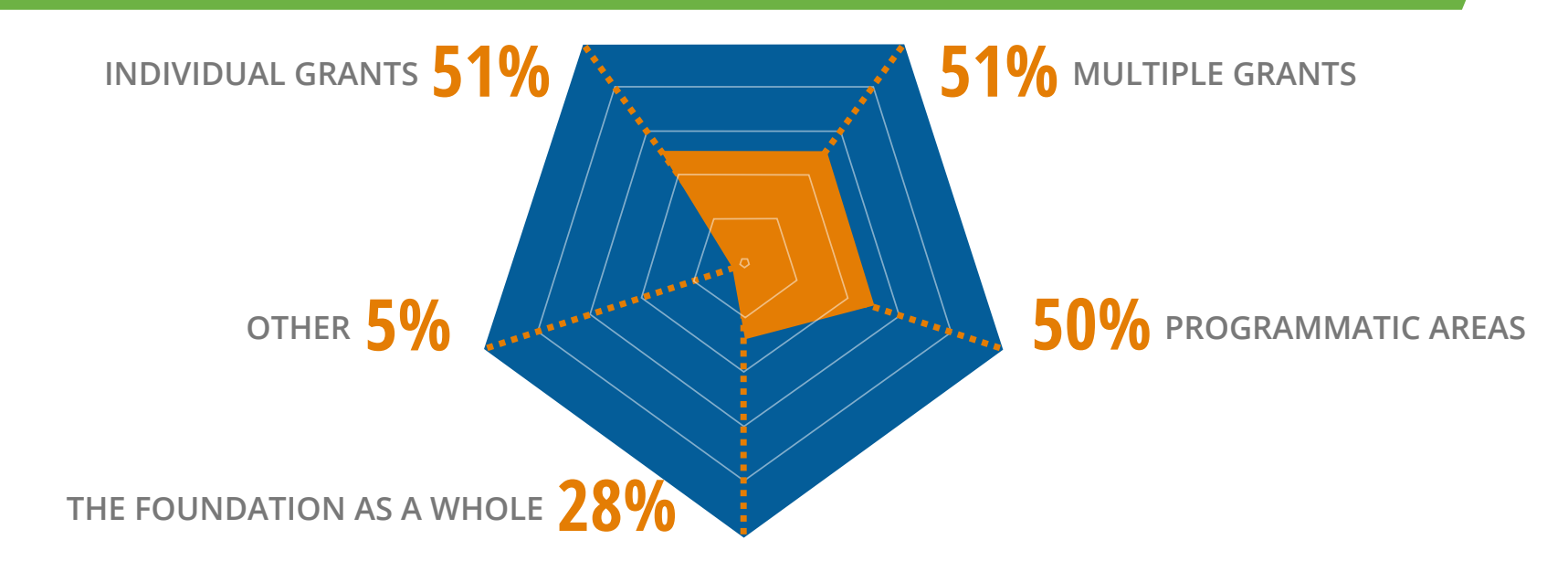

DO FOUNDATIONS SHARE WHAT THEY ARE LEARNING?

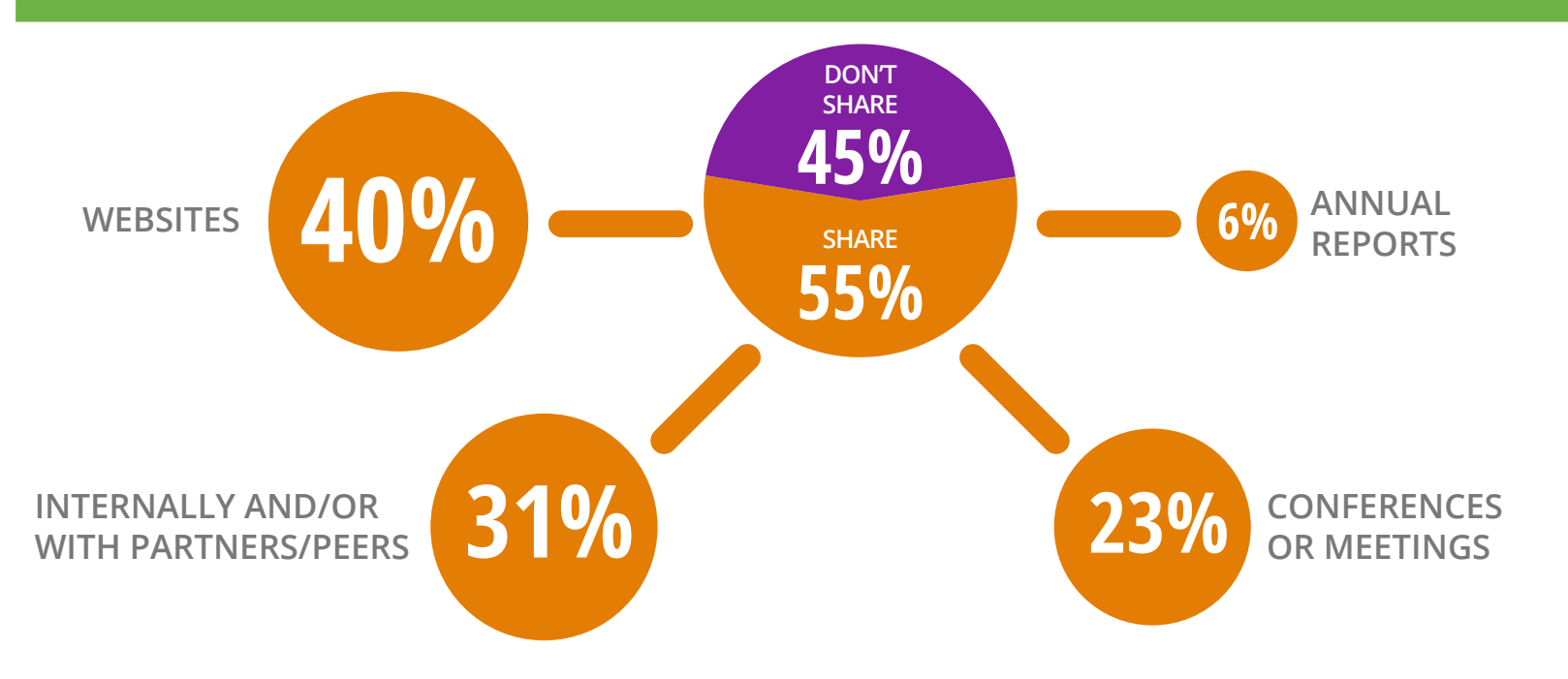

DO FOUNDATIONS LOOK AT WHAT OTHER FUNDERS ARE SHARING?

\title{
${ }_{64 \%}^{N O}$
}

HOW DO FOUNDATIONS USE THE EXISTING EVALUATIVE KNOWLEDGE BASE (INCLUDING THEIR OWN)

IN DECISION MAKING?

\#政 $92 \%$ To better understand what's "worked" and what hasn't for others

\# $80 \%$ To learn how we can improve our work

\#弗 $72 \%$ to vet a specific strategy or approach

曲 $52 \%$ when renewing a grant

\#曲 $44 \%$ course correction 